\title{
Biological Dentistry-Whole Body Health- Shifting the Paradigm in the 21st Century
}

\author{
Anita Vazquez Tibau ${ }^{1 *}$ and Blanche D Grube ${ }^{2}$ \\ ${ }^{1}$ Center for Environmental and Toxicological Research, University of Puerto Rico, Puerto Rico \\ ${ }^{2}$ Grube is the International Academy of Biological Dentistry \& Medicine (IABDM), Pennsylvania
}

Submission: March 17, 2020; Published: April 08, 2020

*Corresponding author:Anita Vazquez Tibau, Center for Environmental and Toxicological Research, University of Puerto Rico, San Juan, Puerto Rico

keywords: Focal infection theory; Head; Bacteriology; Pathology; Rheumatology; Immunology; Otolaryngologic indicators; Rheumatic diseases; Sinus infections; Myalgia; Neuralgia

\section{Short Communication}

For almost two hundred years dentistry has gone through many changes. Some of the changes have been good, and some of the good changes, have been dismissed as bad. The dismissal of "The Focal Infection Theory" for example, is now proving to have been very bad. In the early 1900's, Dr. William Hunter brought forward the idea of dental infections as being the cause of diseases [1]. Others came after Hunter, such as Dr. Frank Billings, where the term, "Focal Infection Theory" was first introduced.

Billings noted that the focus of infection usually occurred in the head, and in teeth that had excessive dental work. He stated that tonsils were especially at risk. Dr. Edwin Rosenow, followed Billings, and continued researching the Focal Infection Theory, saying that root canal procedures should cease [2]. The dentists and doctors who were devotees of the Focal Infection Theory were called the "one hundred percenters", because they took what would have appeared to be drastic measures in oral health care, by removing all teeth to prevent diseases from allergies to schizophrenia.

They also would perform tonsillectomies as part of their protocol [3]. While all the of the doctors mentioned above, made tremendous advancements in dentistry, the research of Dr. Weston Price, was the most prolific and meticulous. Price worked with the highly regarded luminaries of the day, such as Charles Mayo, Victor Vaughn, Milton Rosenau and others. In fact, he had a research team of sixty scientists from various branches of medicine and dentistry that included experts in bacteriology, pathology, rheumatology, immunology, chemistry, cardiology, and surgery.
He spent 25 years investigating endodontically treated teeth and pulp less teeth as a continuation of the Focal Infection Theory. Dr. Price's impeccable research on root canal teeth and its causation of many diseases was done by removing the tooth and placing it into a rabbit. Whatever the disease of the patient, the rabbit would develop the same disease symptoms. Price would replicate this thousands of times. Many times, the original donor sample would be placed in multiple rabbits and again, the rabbits would develop the same disease [4].

Some years later, the Focal Infection Theory was deemed to be "flawed" citing poor controls and massive doses of bacterial inoculum that were used in the scientific studies. The endodontic practioners completely rejected this theory, even though it had been shown to have a basis of fact in the scientific literature [3]. The Focal Infection Theory is now being revaluated, and current research is proving that many of today's diseases do in fact start in the mouth. The World Health Organization (WHO) has stated that oral infections affect half of the world's population, with severe periodontal disease as the eleventh most prevalent disease globally. Dental disease is now a global pandemic [5]. Many of the most common dental procedures such as; root canal treatments, dental implants, nickel braces, and ordinary tooth extractions are being investigated as the causation of diseases.

There are still missing pieces in dentistry, however, one very important piece that dentists are not looking at, is the toxicity of the dental materials they are using, and how these materials interact with each other over a period of time. This is a serious problem, particularly when multiple metals are used that were 


\section{Global Journal of Otolaryngology}

once thought to be inert, such as; mercury dental amalgam, a restorative material that has been used for almost as long as modern dentistry has been in existence. Dental mercury amalgam contains about $50 \%$ mercury, a known neurotoxin.

Titanium is not only used in dental implants, but also in many dental materials and has shown to be toxic. Nickel braces, are often called "stainless steel", as are nickel crowns. Nickel has been deemed to be carcinogenic, according to the National Toxicology Program, Department of Health and Human Services. When oral galvanism occurs, particles are released from the oral cavity and can translocate to other areas in the body, causing potential toxicity and biological hazards. These common dental metals and materials are not only a risk of exposure for the patients, but also for the dentist and the dental workers, when placing and removing these materials [6].

What has also happened is that dentists have taken the role of "tooth mechanics" without the understanding that the oral cavity is the foundation, for whole body health. This is because the majority of dental professionals are only looking at the functionality of the procedures that are all too common in dentistry. Naturally the ears, eyes, nose, and throat, are closest to the oral cavity, which is why they too, would be affected by the mouth.

Harper et al. [7] noted that about 70\% medical teaching institutions commonly have only 4 hours or less on oral health, with $10 \%$ having no oral health in their curriculum, at all. Health care providers have performed physical assessment of the head, ears, eyes, nose, and throat (HEENT) in the same fashion since its inception centuries ago. For the majority of primary care providers, the traditional HEENT examination excludes examination of the oral cavity, as well as omitting oral health and its linkages to overall health in the health history. By adding an 0 (oral) to HEENOT, the NYU College of Nursing and the College of Dentistry are working to bridge the gap and make it an essential element in primary care [7].

Since the majority of medical students are not being introduced to ear, nose, throat, otolaryngology and dentistry, this area of the body continues to be a mystery. Their only encounter with this area is because of trigeminal pain due to trigeminal neuralgia, which are explored in the cases of neurosurgical procedures. While there are many possible reasons for severe orofacial pain, its origin is usually from a dental source. Orofacial pain conditions include sinuses, salivary gland, ears, eyes, throat, mandibular, and maxillary bone pathology. Therefore, it is critical to have an understanding of how common dental problems can be successfully treated and eliminate the source of pain safely and effectively [8].

There has long existed a colossal chasm between medical doctors and the dental profession that is only now starting to close, particularly in the world of integrative medicine. Current research has shown that $30-40 \%$ of chronic maxillary sinusitis cases are caused by oral conditions. The infections of the maxillary posterior teeth, pathologic lesions of the jaws and teeth, dental trauma, or by iatrogenic causes, such as dental and implant surgery, are linked to sinusitis [9]. Using the data base of the Korean National Health Survey, Kim et al. looked at the relationship between temporomandibular joint disorder (TMD) and tinnitus.

After adjusting for all covariates of the 11,745 participants, they found that those who had TMD had more tinnitus than those without TMD. Furthermore, individuals that had dental pain in addition to TMD had a higher occurrence of tinnitus than TMD alone [10]. According to Zope et al. [11] ear pain is often very easy to establish and resolve, however, while the pain presents itself in the ear, the source may actually be dental related. Common ear pain can be caused by impacted teeth, dental infections, neuralgia, sinus infections, TMD, and myalgia of masticatory muscles along with other conditions. They concluded that it is important to work in conjunction with a dental professional for positive outcomes [11].

A pilot study was conducted to investigate the relationship between the oral microbiome and dental health in primary open angle glaucoma. Open angle glaucoma is the most prevalent of all glaucoma cases worldwide, affecting about $70 \%$ of those who are diagnosed with this condition. While the study sample size was small, along with limited resources and other limitations, from the research gathered, they felt from a public health perspective that it would be "worthwhile exploring the possibility of glaucoma prevention in high risk populations by improving dental care" [12]. Akhtar et al. [13] reported that dental infections and dental extractions are a predisposing risk factor for conceivable lifethreatening infections of the head and neck. This is a particular risk, due to unsanitary conditions and for patients with compromised immune systems, in developing countries [13].

The link between oral manifestations of autoimmune rheumatic diseases was investigated by Abrao et al. [14] noting that it is commonly ignored in clinical practice. Many autoimmune rheumatic diseases are possibly originating in the mouth, such as rheumatoid arthritis, inflammatory myopathies, systemic sclerosis, systemic lupus erythematosus, relapsing polychondritis, and Sjögren's syndrome. These oral indications such as hypo salivation, xerostomia, temporomandibular joint disorders, and lesions of the oral mucosa, periodontal disease, dysphagia, and dysphonia may be precursors of rheumatic diseases [14].

A study by Gera and Kumar investigated the awareness and practice amongst a group of 29 otolaryngologists, to see their knowledge base on otolaryngologic indicators of rheumatic diseases. The above-mentioned rheumatic diseases are frequently seen by otolaryngologists, because patients that have ENT problems, go to them first. This paper reports that awareness of these symptoms are slight, and that early and precise diagnosis, along with pre-emptive treatment or referral to specialists, may prevent illness or death. They found that while there was an awareness of otolaryngologic manifestations of rheumatic diseases, their index of suspicion, as well as practical knowledge 
and confidence for evaluation of such diseases were not sufficient [15].

What can we do to really achieve remarkable healing results for the patient, instead of simply treating disease symptoms? A simple visual examination of a patient's mouth can often provide insight as to what may be causing health issues, or can possibly prevent a potential disease risk. All medical professionals can easily implement this straightforward procedure with each patient. We believe that it is necessary to create a real partnership between both the medical and dental profession, and most importantly the patient. We also believe that this is a feasible solution, because one profession cannot do this alone, and of course, this cannot be achieved without the patient's participation.

\section{References}

1. Hunter W (1900) Oral Sepsis as a Cause of Disease. Br Med J 2(2065): 215-216.

2. Gibbons RV (1998) Germs, Dr. Billings, and the Theory of Focal Infection. Clinical Infectious Diseases 27: 627-633.

3. Kumar PS (2017) From focal sepsis to periodontal medicine: a century of exploring the role of the oral microbiome in systemic disease. J Physiol 595(2): 465-476.

4. Price WA (1922) Dental Infections and the Degenerative Diseases.

5. World Health Organization (2016)
6. Tibau AV, Grube BD, Velez BJ, Vega VM, Mutter J (2019) Titanium exposure and human health. Oral Science International 16(1): 15-24.

7. Haber J, Hartnett E, Allen K, Hallas D, Dorsen C, et al. (2015) Putting the Mouth Back in the Head: HEENT to HEENOT. Am J Public Health 105(3): 437-441.

8. Renton T (2011) Dental (Odontogenic) Pain. Rev Pain 5(1): 2-7.

9. Simuntis R, Kubilius R, Vaitkus S (2014) Odontogenic Maxillary Sinusitis: A Review. Stomatologija, Baltic Dental and Maxillofacial Journal 16: 39-43.

10. Kim YH, Park KD, Vu D, Han KD, Cho KH, et al. (2018) Prevalence of Tinnitus According to Temporomandibular Joint Disorders and Dental Pain: The Korean National Population-based Study. Journal of Oral Rehabilitation 45(3): 198-203.

11.Zope SA, Suragimath G, Nilesh K (2017) Referral to Dentist in Clinical ENT Practice. J Otolaryngol ENT Res 6(1): 00151.

12. Polla D, Astafurov K, Hawy E, Hyman L, Hou W, et al. (2017) A pilot study to evaluate the oral microbiome and dental health in primary open angle glaucoma. J Glaucoma 26(4): 320-327.

13. Akhtar N, Saleem M, Mian FA, Shareef MJ, Hussain F (2015) Head and Neck Infections; Secondary to Dental Causes; Diagnosis and Treatment. Med J 22(6): 787-792.

14. Abrão AL, Santana CM, Bezerra AC, Amorim RF, Silva MB, et al. (2016) What rheumatologists should know about orofacial manifestations of autoimmune rheumatic diseases. Rev Bras Reumatol 56(5): 441-450.

15. Gera C, Kumar N (2015) Otolaryngologic Manifestations of Various Rheumatic Diseases: Awareness and Practice Among Otolaryngologists. Indian J Otolaryngol Head Neck Surg 67(4): 366-369.

\section{Your next submission with Juniper Publishers will reach you the below assets}

- Quality Editorial service

- Swift Peer Review

- Reprints availability

- E-prints Service

- Manuscript Podcast for convenient understanding

- Global attainment for your research

- Manuscript accessibility in different formats ( Pdf, E-pub, Full Text, Audio)

- Unceasing customer service

Track the below URL for one-step submission https://juniperpublishers.com/online-submission.php 
